\title{
A CRISE DA PANDEMIA DA COVID-19 DESNUDA O RACISMO ESTRUTURAL NO BRASIL
}

\section{THE COVID-19 PANDEMIC CRISIS EXPOSES STRUCTURAL RACISM IN BRAZIL}

\author{
Fernanda Gonçalves Sthel \\ Universidade Estadual do Norte Fluminense, Centro de Ciências do Homem, Laboratório de Estudos da \\ Sociedade Civil e do Estado. Av. Alberto Lamego, 2000, Campos dos Goytacazes, Rio de Janeiro - RJ, Brasil, CEP \\ 28013-602. \\ E-mail: sthel308@gmail.com | ORCID: https://orcid.org/0000-0001-9858-9850

\section{Luciane Soares da Silva} \\ Universidade Estadual do Norte Fluminense, Centro de Ciências do Homem, Laboratório de Estudos da \\ Sociedade Civil e do Estado. Av. Alberto Lamego, 2000, Campos dos Goytacazes, Rio de Janeiro - RJ, Brasil, CEP \\ 28013-602. \\ E-mail: lucianecoltrane@gmail.com | ORCID: https://orcid.org/0000-0003-1395-3305
}

\begin{abstract}
Resumo: A pandemia causada pelo SARS-CoV-2 trouxe um novo desafio para a humanidade. O Brasil, por suas características de desigualdade extrema, foi impactado severamente pela COVID-19. Estes impactos foram particularmente severos entre a população negra. O objetivo deste trabalho é analisar se o racismo estrutural se reflecte na taxa de mortalidade por COVID-19 da população negra, nas cidades do Rio de Janeiro e de São Paulo. Os dados utilizados foram obtidos de fontes oficiais como IBGE, Agência Pública, Ministério da Saúde e as Secretarias Estaduais de Saúde. Os resultados mostraram que a população negra se tornou a maior vítima da doença. A média de óbitos entre negros é de 60,7\% em comparação com as pessoas brancas que somaram $37,2 \%$ das mortes. Este estudo revela que a pandemia se tornou uma verdadeira tragédia para a população negra brasileira.
\end{abstract}

Palavras-chave: COVID-19, racismo estrutural, desigualdade social, Brasil.

Abstract: The pandemic caused by SARS-CoV-2 brought a new challenge for humanity. Brazil, particularly due to its extreme inequality, was severely impacted by COVID-19. These impacts were particularly pronounced among the black population. This work aims to analyse whether the latent structural racism in Brazil is reflected in the mortality rate of the black population by COVID-19, in the cities of Rio de Janeiro and São Paulo. Data were gathered from official sources such as IBGE, Agência Pública Ministry of Health and the State Health Secretariats. The results showed that the black population became the biggest victim of this disease. The average number of deaths among blacks is $60.7 \%$ compared to white people, who accounted for $37.2 \%$ of deaths. This study reveals that the pandemic has become a real tragedy for the Brazilian black population.

Keywords: COVID-19, structural racism, social inequality, Brazil.

\section{Introdução}

Na cidade chinesa de Wuhan, no final do ano de 2019, foram relatados casos de uma pneumonia desconhecida e, em janeiro de 2020, o vírus foi identificado e 
intitulado de SARS-CoV-2 (WHO, 2020a). Esse vírus causou uma nova doença denominada de COVID-19 e se espalhou rapidamente por todos os continentes. Tal disseminação foi classificada como pandemia pela Organização Mundial de Saúde (WHO, 2020b). No início de janeiro de 2021, já se computava mais de 1 milhão e 850 mil vítimas fatais no mundo, causando um colapso na economia global (Partington, 2020; Javorcik, 2020). No início de fevereiro de 2020, antes de o primeiro caso ser diagnosticado no Brasil, foi decretada emergência de saúde pública (Croda et al., 2020). O primeiro caso confirmado de COVID-19 no Brasil ocorreu em 26 fevereiro de 2020, na cidade de São Paulo, em um passageiro vindo da Itália.

É fundamental pontuar que o Brasil apresentou outro desafio: o discurso negacionista (Phillips \& Briso, 2020) do governo federal em relação aos riscos da doença, fato que contribuiu para o recrudescimento da pandemia no país, devido à falta de uma liderança nacional coesa e do incentivo à aglomeração e ao não uso de proteção facial. A carência de organização e seriedade do governo Bolsonaro implicou diversos fatores como, por exemplo, o rodízio de ministros da saúde durante o ano de 2020. Nesse ano, o Ministério da Saúde passou pela gerência de três diferentes ministros (Cancian, 2020) em um curto período. Sendo dois desses demitidos por se contrapor às ordens do presidente ${ }^{1}$. Essa troca frequente acarretou atrasos nas operações de saúde, aumento de gastos públicos além de instabilidade pública e política. Os impactos negativos na sociedade e na economia brasileira são crescentes, contando com mais 196 mil mortos e mais de 7 milhões e 700 mil infectados em janeiro de 2021.

O Estado do Rio de Janeiro iniciou o seu isolamento social em 16 de março, declarando emergência de saúde pública e determinando o fechamento de espaços públicos. Em 19 de março, saiu um novo decreto no qual comércios em geral, tais como restaurantes, shoppings e bares deveriam encerrar seu funcionamento a partir de 21 de março. As atividades de serviços básicos e de saúde não foram interditadas, assim como as indústrias (Decreto $n^{\circ} 46.980 / 2020$ ). Ressalta-se que a capital possui cerca de 6 milhões de habitantes (IBGE, 2010a) e, em agosto, possuía em torno de 88 mil infectados e 9 mil vítimas fatais. Limitações similares foram adotadas no Estado de São Paulo que decretou um isolamento social no dia 24 março (Decreto $\left.\mathrm{n}^{\mathrm{o}} 64.881 / 2020\right)$. Sua capital, São Paulo, é a maior cidade da América Latina e possui uma população de aproximadamente 12 milhões de habitantes (IBGE, 2019b). A cidade apresentou o maior número de casos e mortes notificado no país, em torno de 280 mil casos e 11 mil mortes.

1 Os ministros Luiz Henrique Mandetta e Nelson Teich foram demitidos por não aceitarem o tratamento sem comprovação científica (hidroxicloroquina) sugerido pelo presidente Jair Bolsonaro. 
No Brasil, os primeiros casos da COVID-19 foram diagnosticados em áreas nobres das grandes cidades e em indivíduos que transitam internacionalmente. Posteriormente, espalhou-se pelas regiões periféricas, onde a marca da desigualdade social aparece de forma mais proeminente. Devido ao racismo estrutural no Brasil, a população negra - pretos e pardos - foi historicamente marginalizada, concentrando-se nas regiões mais pobres das cidades e, consequentemente, sendo mais vulneráveis socialmente. Essa população representa apenas $27,7 \%$ entre os $10 \%$ mais ricos do Brasil, e em pobreza representa $75,2 \%$ entre os $10 \%$ mais pobres (IBGE, 2019a). Além de possuir pouco acesso à medicina preventiva, visto que o sistema de saúde pública é precário. Além disso, segundo o Ministério da Saúde, a população negra possui majoritariamente doenças como diabetes, hipertensão e anemia falciforme (Ministério da Saúde, 2017).

Essa conjunção de fatores resulta em uma maior vulnerabilidade dos negros em relação aos brancos, mostrando a face mais perversa do racismo que persiste no Brasil. Tanto no Brasil como nos Estados Unidos, países em que houve um sistema escravocrata de larga escala sem a devida reparação histórica, a população de pretos e pardos se encontra mais exposta à COVID-19. Em função disso, o objetivo deste trabalho é analisar a taxa de mortalidade por COVID-19 em populações negras e as possíveis causas ligadas ao racismo estrutural brasileiro, a fim de responder à seguinte pergunta de pesquisa: $O$ racismo estrutural no Brasil potencializa os efeitos da pandemia da COVID-19 no que tange à taxa de mortalidade entre os negros? Esse quadro não é particular apenas ao coronavírus. Em 1918, no auge da Gripe Espanhola no Brasil, a população de pretos e pardos também representou o grupo mais vulnerável à doença, confirmando o caráter estrutural da pandemia.

\section{Metodologia de pesquisa}

Para os cientistas, a pandemia tem colocado outro desafio, particularmente nas ciências humanas, o qual afeta a pesquisa de campo. Como pesquisar em quadros de obrigatório isolamento? Como captar os quadros sociais emergentes (saúde mental, idosos, relações domésticas, infância, justiça e gênero, morte e raça), usando meios eletrônicos? É fato que as pesquisas estatísticas apresentam os dados sobre infecção, número de mortos, leitos e outros dados úteis para o mapeamento quanto à evolução da COVID-19. Nesse sentido, optamos pelo emprego da análise documental, técnica que privilegia o uso de fontes produzidas por terceiros. Considerando sua utilidade, devemos também advertir que existem limites no uso dessa técnica ${ }^{2}$. No caso específico da pandemia, estamos trabalhando com um objeto cujas alterações são diárias. Não apenas em 
números, mas também nas formas de debate, na geopolítica das soluções entre os países e nas discussões mais amplas sobre políticas públicas de saúde, de assistência social e emprego.

Os dados obtidos foram referentes ao Brasil, em escala macro, e às duas maiores cidades do País - Rio de Janeiro e São Paulo -. Isso se deve à disponibilidade dos dados oficiais para essas duas cidades nos primeiros meses da pandemia os quais eram, consideravelmente, mais abrangentes do que em outras localidades, devido à proporção populacional e infraestrutura das duas grandes capitais. Esta pesquisa buscou registrar os primeiros meses - abril a julho - da pandemia da COVID-19 no Brasil, no que tange à identificação da maior taxa de mortalidade entre os negros. Os dados ainda estavam sendo coletados pelas agências oficiais do país, por se tratar de um evento em curso. Além disso, os dados do Ministério da Saúde só passaram a incluir a cor das vítimas em 11 de abril, depois de muita pressão de entidades representativas. Para se manter a confiabilidade dos dados, buscamos utilizar fontes oficiais como IBGE, Agência Pública, Ministério da Saúde e Secretarias de Saúde, além de jornais e revistas online consultados diariamente. Avaliando, conjuntamente, as referências bibliográficas que confirmam a grave desigualdade social e o racismo no Brasil.

\title{
Racismo estrutural no Brasil
}

Segundo o decreto da Convenção Internacional sobre a Eliminação de Todas as Formas de Discriminação Racial (Organização das Nações Unidas [ONU], 1965), o racismo é

\begin{abstract}
Qualquer distinção, exclusão, restrição ou preferência baseada em raça, cor, descendência ou origem nacional ou étnica que tenha por objeto ou resultado anular ou restringir o reconhecimento, gozo ou exercício em um mesmo plano (em igualdade de condição) de direitos humanos e liberdades fundamentais nos campos político, econômico, social, cultural ou em qualquer outro campo da vida pública (Art. ${ }^{\circ} 1^{\circ}, \mathrm{n}^{\circ} 1$ ).
\end{abstract}

A origem do racismo é fruto do conceito de raça que categoriza indivíduos vivos em grupos baseados em seus fenótipos. "É o fenótipo que serve de linha de demarcação entre os grupos raciais, e como ponto de referência em torno do qual se

2 Uma dificuldade apresentada foi a tentativa do Governo Bolsonaro de omitir as publicações diárias dos dados, reduzindo a quantidade e a qualidade dos mesmos o que obrigou os órgãos de imprensa a formarem um consórcio para produzirem informações mais confiáveis sobre a pandemia. 
organizam as discriminações 'raciais'" (Wedderburn, 2007, p. 11). O termo racismo em si, surge através da ciência do século XIX, a partir de teorias científicas produzidas por médicos, antropólogos e biólogos que buscavam determinar uma superioridade racial, a fim de justificar as dominações europeias da época - imperialismo e neocolonialismo - , e exterminações em massa como o projeto nazista de Hitler, influenciado pelas teorias eugenistas e de darwinismo social. Essas teorias trouxeram uma interpretação de "raça pura e evoluída" que representava o povo branco europeu, e "raça inferior atrasada" qualquer outro povo que não condizia com os fenótipos caucasianos do Norte. Segundo Bolsanello,

O darwinismo social considera que os seres humanos são, por natureza, desiguais, ou seja, dotados de diversas aptidões inatas, algumas superiores, outras inferiores. A vida na sociedade humana é uma luta "natural" pela vida, portanto é normal que os mais aptos vençam, tenham sucesso, fiquem ricos, tenham acesso ao poder social, econômico e político; da mesma forma é normal que os menos aptos fracassem, não fiquem ricos, não tenham acesso a qualquer forma de poder. (Bolsanello, 1996, p. 154)

Essas teorias racistas eram de fato ideológicas, cujo objetivo era defender a sociedade capitalista e manter a manutenção de poder (Bolsanello, 1996, p. 155), proporcionando a absoluta institucionalização das dominações imperialistas e neocolonialistas o que, de fato, perdurou até a contemporaneidade. O racismo é um elemento político e está engendrado na sociedade, tal como explicita Almeida, "o racismo é a manifestação normal de uma sociedade, e não um fenômeno patológico ou que expressa algum tipo de anormalidade" (Almeida, 2018, p. 21), ou seja, é comum, é estrutural e, sobretudo, institucional.

O processo de escravidão no Brasil se inicia no século XVI, com a necessidade da ampliação de mão de obra para o cultivo da cana açúcar. Esse processo deslocou milhões de africanos para o Brasil nos três séculos que se sucederam. O preconceito com a cor da pele, a intolerância religiosa e cultural e o trabalho braçal favoreceram a criação de um estigma negativo em relação aos negros, além de os próprios escravocratas enxergarem a escravidão como escória, acreditando que os negros estavam naquela situação por serem uma raça inferior (Schwarcz \& Starling, 2015). Certamente, a experiência do racismo no Brasil é completamente particular, moldada através dos entraves da estrutura histórica.

De acordo com Joaquim Nabuco, teórico e abolicionista, toda a sociedade é atravessada pela escravidão, "O nosso caráter, o nosso temperamento, a nossa organização toda, física, intelectual e moral, acha-se terrivelmente afetada pelas influências com que a escravidão passou trezentos anos a permear a sociedade brasileira." (Nabuco, 2012, p. 13). Dialogando com essa questão, está a discussão de 
Florestan Fernandes (2008) sobre as etiquetas da sociedade brasileira do século XX, em que os agentes sociais estabeleciam uma série de comportamentos considerados aptos socialmente, os quais não eram compartilhados pelas pessoas negras da época. "Se o 'negro' deixasse de corresponder, de modo próprio, às expectativas convencionais, impunha-se 'lhe dar uma lição'” (Fernandes, 2008, p. 315). É o que, com certeza, acontece com o racismo, em uma sociedade ocidental baseada em características fenotípicas e culturais europeias.

Uma das raízes do racismo estrutural brasileiro consiste na teoria da democracia racial, que representa a ideologia de que brancos, negros, indígenas e outros se relacionavam pacificamente devido à miscigenação, possibilitando a existência de uma raça-híbrida (Freyre, 2006). "A contribuição brasileira para a civilização seria a cordialidade, o 'homem cordial'" (Holanda, 1936, p. 176). Segundo Holanda (1936), a generosidade e a hospitalidade são virtudes saudadas por estrangeiros quando visitavam o Brasil e o temperamento brasileiro admite formas de reverência e de apego frequente aos portugueses. O que, segundo o sociólogo Florestan Fernandes, reforça a estrutura racista e impede as transformações necessárias, “Os fatos - e não as hipóteses - confirmam que o mito da democracia racial continua a retardar as mudanças estruturais" (Fernandes, 1989, p. 16).

Essas teorias fundamentadas, no Brasil, trouxeram a crença de que não existe racismo no país; pois, por ser de característica miscigenada, haveria teoricamente uma democracia racial em que não fosse possível a existência de qualquer preconceito étnico, além da imagem do brasileiro cordial e benevolente, que não poderia causar algum mal ao seu próximo. Fernandes (2008), em seus estudos sobre o mito da democracia racial, concluiu que a imagem do "bom negro", que representava submissão e lealdade ao branco, favoreceu a manutenção do racismo e dos interesses dominantes. "Quanto mais o negro e o mulato se identifiquem com os ideais da personalidade democrática, concatenados em torno da figura do cidadão e dos direitos fundamentais da pessoa, tanto mais eles são incompreendidos, avaliados etnocentricamente e depreciados." (Fernandes, 2008, p. 318).

Outra questão é o processo de "embranquecimento" do Brasil, que tem a marca da miscigenação como um sistema ideológico e se apresenta como uma medida de antirracismo; porém, na realidade, revela um racismo intrínseco em relação ao negro; pois admite uma concepção evolucionista da humanidade para um caminho branco, segundo d'Adesky (1997).

Abdias do Nascimento (1978) retrata, em sua obra, os fatores que contribuíram para esse processo de "embranquecimento". Segundo o autor, ele está associado a um processo de mulatização, proveniente da exploração sexual das mulheres negras, o qual "retrata um fenômeno puro e simples de genocídio" (Nascimento, 
1978, p. 69). A política migratória também foi um instrumento crucial nesse processo embranquecedor. Em vários momentos, a Câmara dos Deputados discutiu leis nas quais se proibia a imigração de indivíduos de cor preta no Brasil, estimulando a entrada de imigrantes brancos do continente europeu (Nascimento, 1978, p. 71). "A assunção prevalecente, inspirando nossas leis de imigração, considerava a população brasileira como feia e geneticamente inferior por causa da presença do sangue negro-africano." (Nascimento, 1978, p. 70). Além disso, era estimulada pelo governo a imigração de racistas expulsos das recém-liberadas colônias africanas. Ainda sobre o ideal de branqueamento brasileiro, as autoras Maia e Zamora (2018) sinalizam o funcionamento dessa política estabelecida.

A política de branqueamento não é a única iniciativa de Estado responsável pelos efeitos do racismo na população; porém, sua permanência ainda é produtora de sofrimento psíquico e social. O conjunto das instituições republicanas, como o judiciário, o sistema educacional, as leis e as políticas públicas, entre outras, são uma rede tecida nas bases do racismo científico. A política do "embranquecimento" é parte dessa rede, constituindo-se e capitalizando-se nos planos mais sutis, micropolíticos, da história brasileira (Maia \& Zamora, 2018, p. 280).

Vale destacar que essa política contribuiu para sedimentar o racismo estrutural no Brasil e, segundo as autoras, para "a substancialidade de seus efeitos no fortalecimento da supremacia da coloração branca, na relação cotidiana com outras cores e etnias brasileiras." (Maia \& Zamora, 2018, p. 280). O racismo estrutural, segundo Almeida (2018), é a forma como o racismo está intrínseco na estrutura social, fazendo com que negros estejam vulneráveis às mazelas sociais e sejam associados automaticamente a estigmas negativos. Segundo o autor, todos os aspectos da sociedade, da política à economia encontram-se atravessados pelo racismo. E as instituições, sejam públicas ou privadas, contribuem para a reprodução dessa postura racista. De acordo com Oliveira e Carvalho (2017, p. 229), o racismo estrutural reflete a forma como a sociedade enxerga a questão racial, pois ele está construído social e politicamente como um padrão. Ou seja, o racismo, sociologicamente falando, é uma opressão sistêmica.

A branquitude pode ser definida como uma posição em que os indivíduos participantes são privilegiados historicamente no que tange a bens materiais ou simbólicos, mantendo-se nesse espaço na contemporaneidade (Schucman, 2014, p. 84). Em relação ao significado da branquitude, pressupõe-se a ideia de que brancos não possuem raça nem etnia e não se encaixariam de forma alguma nos grupos de minorias raciais ou étnicas (Cardoso, 2008, pp. 173-198). Essa branquitude, historicamente, criou o conceito de "raça" para justificar a subjugação às pessoas negras e estabeleceu uma hegemonia em espaços de poder e instituições, 
possibilitando somente pessoas brancas ocuparem esses locais, facilitando assim o processo de dominação.

Os primeiros a falarem sobre racismo institucional foram os autores Stokely Carmichael e Charles V. Hamilton (1967) os quais analisaram o racismo na sociedade estadunidense do final da década de 60. É muito marcante em suas obras a diferenciação de racismo individual, que se refere a indivíduos brancos hostilizando indivíduos negros e racismo institucional, que representa toda a comunidade branca em contraposição a comunidade negra. O racismo institucional representa a reprodução do racismo pelas instituições de poder, estas que possuem uma alta relevância nas ações sociais e, por serem vislumbradas de modo diferente pela sociedade, não são perceptíveis para a maioria das pessoas, sendo muito mais sutis, apesar de ser, indubitavelmente destrutivo (Carmichael \& Hamilton, 1967). Já segundo Almeida, o racismo institucional "significa que a imposição de regras e padrões racistas por parte da instituição é de alguma forma vinculada à ordem social que ela visa regular" (Almeida, 2018, p. 47). Para Foucault (1976/2005), pode ser considerado como um "racismo de estado".

Um racismo de Estado: um racismo que uma sociedade vai exercer sobre ela mesma, sobre os seus próprios elementos, sobre os seus próprios produtos; um racismo interno, da purificação permanente, que será uma das dimensões fundamentais da normalização social. (Foucault, 1976/2005, p. 73)

Portanto, o racismo institucional não se expressa em atos explícitos e escancarados, mas sim atua de forma cotidiana no funcionamento das organizações e instituições que promovem as políticas públicas, gerando mais desigualdades e iniquidades (López, 2012, p. 127). Segundo os trabalhos de Loureiro e Rozenfeld (2005), Lopes (2005) e Batista (2005) (citados em Kalckmann et al., 2007), o racismo institucional na área da saúde afeta majoritariamente as populações negras, expondo-as a dificuldades no acesso aos serviços de saúde, à má qualidade de atendimentos e invisibilizando suas necessidades o que determinam as diferenças de adoecimento e morte entre negros e brancos.

O racismo, no Brasil, é tão profundamente enraizado que se apresenta em várias facetas, uma delas é a discussão do racismo ambiental. Esse termo foi cunhado mediante a debates e estudos sobre a justiça ambiental, um movimento que fora iniciado por negros estadunidenses na década de 1980 para denunciar as condições ambientais em que vivia a população negra norte-americana. Esse conceito se enquadra na discussão do artigo, pois está atrelado à vivência de determinadas etnias em condições precárias e degradantes no sentido ambiental, situação que resulta em uma maior indefensabilidade dessas populações perante a desastres naturais 
ou ocasionados. Segundo Bullard (2004) e Acselrad (2004) (citados em Jesus, 2020), o racismo ambiental também é uma forma de racismo institucional; pois, no instante em que há omissão de políticas públicas, as desigualdades sociais e raciais, no contexto ambiental, expandem-se, produzindo iniquidades, exploração política e diversos problemas ambientais.

\section{Desigualdades sóciorraciais no Brasil}

A desigualdade social é a marca indelével da sociedade capitalista, baseada no princípio de acumulação de renda e má distribuição de recursos e gera consequências indesejáveis para a maioria da população. Segundo Piketty, "O capitalismo produz automaticamente desigualdades insustentáveis, arbitrarias, que ameaçam de maneira racial os valores da meritocracia sob os quais fundam nossas sociedades democráticas." (Piketty, 2014, p. 9). O Brasil se apresenta como um dos países mais desiguais do mundo. Dados do Instituto Brasileiro de Geografia e Estatística (IBGE, 2019a) indicam que a renda dos 1\% mais ricos é 34 vezes maior que a renda da metade mais pobre do Brasil. E entre os mais pobres, a população negra é maioria. O rendimento médio per capita da população negra é de $\mathrm{R} \$ 934,00$ enquanto o da população branca é de $\mathrm{R} \$ 1.846$, isto é, duas vezes maior. Em condições de moradia, $44,5 \%$ de pretos e pardos vivem em condições precárias com ausência de serviços básicos (IBGE, 2019a).

O acesso à saúde também é um grande desafio para o Brasil. Foi estabelecido na Constituição Federal de 1988, no artigo 196, o direito universal da saúde, garantindo sua aplicabilidade via políticas públicas, que visam a reduzir o risco de doenças e o acesso de todos a um sistema universal de saúde, porém na prática, não funciona como deveria. Apesar de sua grande importância e papel relevante, o Sistema Único de Saúde (SUS) tem sido esfacelado nos últimos anos. Seja por déficit das contas públicas, má organização e corte de gastos, o sistema se apresenta quebrado em diversas situações.

Além disso, tradicionalmente, o Brasil não investe em saúde o suficiente para a demanda de sua população, e essa situação se agravou devido à Emenda Constitucional $n$. $^{\circ} 95$, que limitou o teto de gastos públicos o que retirou 20 bilhões doSUS no ano de 2019 (Conselho Nacional de Saúde, 2020). Essa precariedade do sistema de saúde público possibilitou a existência de planos de saúde particulares, que se restringem à população que pode pagar tais mensalidades. Portanto, indivíduos que não possuem condições socioeconômicas são submetidos a realidades degradantes, como insuficiência de serviços, baixa disponibilidade de insumos, quantidade reduzida de profissionais e depreciações. 
Em decorrência do racismo, as populações mais atingidas por essa falha na saúde pública são as de pretos e pardos, representando essas iniquidades raciais. De acordo com Silva et al., em seu estudo relacionado ao acesso da população negra ao sistema de saúde, é perceptível a situação de vulnerabilidade em que essa população se encontra subsumida. "A mortalidade para negros é duas vezes maior que para os brancos em muitas doenças, como, por exemplo, doenças mentais; gestação, parto e puerpério; infecções; doenças hematológicas, endócrinas, dermatológicas e causas externas." (Silva et al., 2020, p. 7).

O saneamento básico brasileiro também é um ponto crítico da desigualdade social, principalmente para o enfrentamento da pandemia. Em 2018, 33 milhões de brasileiros não tinham acesso à água encanada em suas residências, e 95 milhões não possuíam acesso ao tratamento da rede de esgoto (Ministério do Desenvolvimento Regional [MDR], 2018). Além disso, segundo um artigo publicado por $\mathrm{Wu}$ et al. (2020), existe a possibilidade de a COVID-19 estar presente nas fezes de pacientes infectados por quase cinco semanas após os testes terem resultados negativos, o que reafirma as severas consequências da doença em áreas carentes de tratamento de água e esgoto (Capodeferro et al., 2020).

A Figura 1 ilustra outros aspectos da desigualdade racial no Brasil (IBGE, 2019a). Em relação ao mercado de trabalho, a maioria dos cargos gerenciais são ocupados por pessoas brancas, ou seja, a população negra está, em maioria, nos setores subalternos de trabalho. Ademais, entre as pessoas que vivem abaixo da linha da pobreza, a maioria é preta ou parda, sendo que $32,9 \%$ das pessoas negras ganham igual ou inferior a US\$ 5,50/dia e 8,8\% ganham menos de US\$ 1,90/dia. Somando a isso, a taxa de analfabetismo da população negra, também, é consideravelmente maior do que a dos brancos. Outro fator é a violência, pretos e pardos possuem 2,7 mais chances de serem vítimas de homicídio do que brancos. Em 2017, a taxa de homicídios entre jovens negros (de 15 a 29 anos) era mais que o dobro do que para os brancos. E em relação à representação política do país, a minoria entre os deputados federais eleitos são negros. Portanto, esse quadro caracteriza a institucionalidade do racismo brasileiro, que perdura desde a abolição do sistema escravista, sem perspectiva de uma alteração eficiente e definitiva.

De acordo com Fernandes (1989), só existirá de fato uma democracia no Brasil sem desigualdades socioeconômicas quando não houver mais o racismo na estrutura social, ou seja, a luta de classes deve ser conjuntamente à questão racial.

A verdade é que a democracia só será uma realidade quando houver, de fato, igualdade racial no Brasil e o negro não sofrer nenhuma espécie de discriminação, de preconceito, de estigmatização e de segregação, seja em termos de classe, seja 


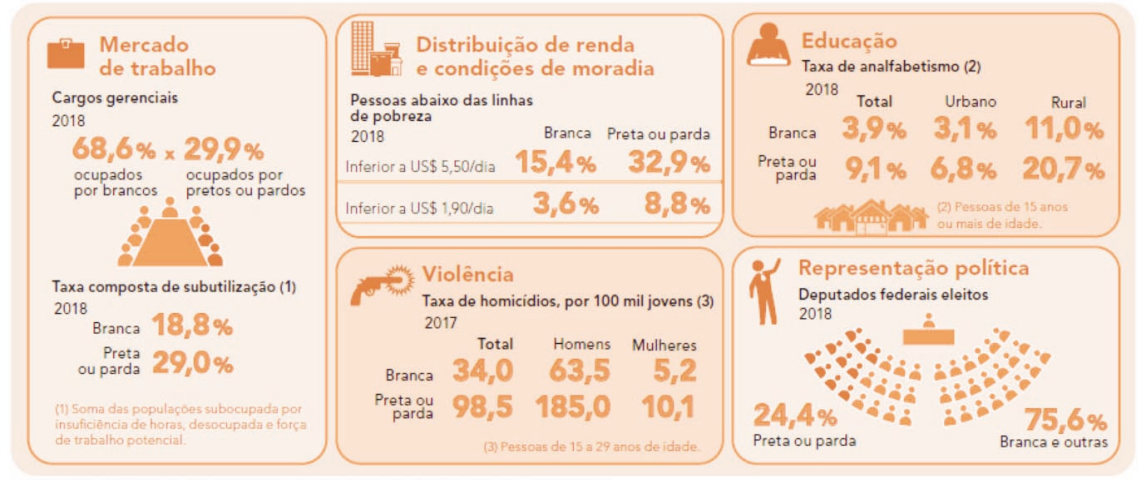

Figura 1 Desigualdades raciais no Brasil

Fonte: IBGE, Diretoria de Pesquisas, Coordenação de População e Indicadores Sociais (2019a).

em termos de raça. Por isso, a luta de classes, para o negro, deve caminhar juntamente com a luta racial propriamente dita (Fernandes, 1989, p. 23).

\section{A crise da COVID-19: aspectos raciais}

O Brasil representa o segundo lugar no mundo em total de óbitos por COVID-19. No mês de março, ocorreu a primeira morte por COVID-19 aqui e a escalada da doença foi implacável, iniciando o mês de janeiro de 2021 com mais de 196 mil mortos. A Figura 2 demonstra a situação dos dez países mais afetados pela doença em janeiro de 2021, a posição ocupada pelo Brasil nesse acompanhamento e aponta, ainda, o número de casos, mortes e recuperados.

Essa tragédia humana, aparentemente universal, atingiria a todos sem distinção de classe ou raça, porém, não foi a realidade. É importante ressaltar que a primeira morte do Estado do Rio de Janeiro - Estado que agrupa uma grande escala em número de óbitos e infectados por COVID-19 - foi uma mulher negra (G1, 2020a) e empregada doméstica de 63 anos de idade, que fora contaminada por sua patroa a qual acabara de voltar da Itália. Segundo as autoras Azevedo e Coly (2020), a concepção de que o vírus seria democrático; na realidade, revela um racismo arraigado na sociedade brasileira.

Sob a falácia de que o vírus seria universal, ratificou-se uma igualdade formal e uma (inexistente) democracia na atual crise biológica, na mais absoluta reafirmação do status quo de uma sociedade que tem o preconceito racial como modo de estrutura social (Azevedo \& Coly, 2020). 


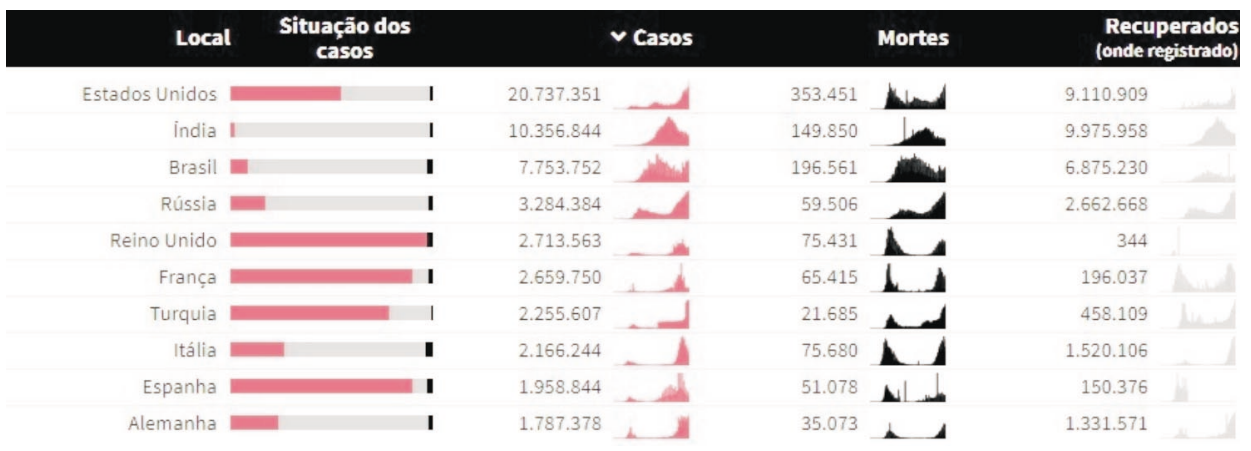

Figura 2 Tabela de acompanhamento da disseminação da COVID-19 em 10 países

Fonte: Reuthers (2001) — (última atualização: 5 de janeiro de 2021 12:25 PM — horário de Brasília, Brasil).

Segundo os autores Baqui et al. (2020), pardos e pretos possuem menos condições econômicas, além de ser pouco provável que possam trabalhar em home office. Tais fatores levaram pessoas negras diagnosticadas com COVID-19 a apresentarem um risco de morte significativamente maior do que as brancas, reafirmando a presença da desigualdade social e do latente racismo estrutural no Brasil.

As consequências do racismo estrutural atreladas à pandemia da COVID-19 não são únicas, já sendo observado o mesmo caso na pandemia da Gripe Espanhola, em 1918, na qual as condições socioeconômicas foram decisivas para exporem a fragilidade dos negros durante a pandemia da Gripe. Segundo o historiador Samuel Adamo (1983, pp. 185-200), que estudou as correlações entre a vida econômica e social da cidade do Rio de Janeiro durante a pandemia, era possível identificar as consequências perversas da Gripe entre os negros, mostrando que a taxa de mortalidade foi maior entre eles, em comparação com os brancos. Nessa época, as condições inseguras de vida marcadas por salários precários, má alimentação, moradias insalubres e falta de acesso à saúde foram características fundamentais nos 30 anos que se sucederam a escravidão. Segundo Bassanezi (2012), em relação ao estudo da Gripe Espanhola no Estado de São Paulo, a população negra também se apresentou mais vulnerável à pandemia.

Os negros, imigrantes e seus descendentes e nativos pobres, incorporados à sociedade paulista, sobretudo, como mão de obra na lavoura cafeeira e nas fábricas, viviam em moradias precárias, em locais com péssimas condições sanitárias e higiênicas. De um modo geral, alimentavam-se mal, eram analfabetos ou semialfabetizados, tinham difícil acesso às informações e ao sistema de saúde (Bassanezi, 2012, p. 19). 
A cidade de Campinas destacou-se, pois apresentou um alto número de óbitos entre a população de não brancos, $42,7 \%$ e estrangeiros - imigrantes da lavoura cafeeira - com 15\% (Bassanezi, 2012). No caso dos negros, eram descendentes de escravos que trabalhavam nas lavouras, estabelecidos após a abolição. "O recenseamento de 1872 mostra Campinas como o maior município escravista das terras paulistas, quase metade da sua população total era escrava $(43,4 \%)$." (Bassanezi, 2012, p. 19).

\section{Resultados e discussões}

Dados de uma pesquisa, realizada em 2020 por 14 pesquisadores do NOIS (Núcleo de Operações e Inteligência em Saúde) da PUC (Pontifícia Universidade Católica) do Rio de Janeiro, mostram a variação entre os óbitos confirmados por COVID-19, e a categorização por idade até a data de 18 de maio (Madeiro, 2020). A média de negros mortos pela doença é maior em todas as idades, principalmente entre $70 \mathrm{a}$ 90 anos, em que tanto a porcentagem de negros como de brancos foi maior, por serem de alto grupo de risco, representando cerca de 80 a $90 \%$ de todos os óbitos. As maiores variações entre brancos e negros é observada nas pessoas mais jovens, nas quais a variação foi o dobro no caso da faixa etária de 20-29 anos, sendo de $10 \%$ para brancos e $20 \%$ para negros, e até quase $20 \%$ de diferença, como é o caso da faixa etária 50-59 anos. Esses dados confirmam o caráter determinante da cor nessa pandemia.

De acordo com dados do SUS da pesquisa realizada pela PUC-RJ (Madeiro, 2020), das mortes em que a cor foi identificada, $54 \%$ eram de pessoas negras, apesar de representarem $51 \%$ da população do país, segundo o IBGE (2010b). A Figura 3 representa a porcentagem de mortes por cor nas regiões do Brasil. Observa-se que a média de óbitos do país é maior nas pessoas negras (pardos e pretos), em comparação com as pessoas brancas. A região Norte, que possui maior parte da população negra do Brasil, houve $74 \%$, de óbitos entre negros, porcentagem maior que a quantidade populacional. No Nordeste, que possui $69 \%$ de negros, também existiu uma quantidade de óbitos superior à população. O Centro-Oeste, com $55 \%$ de sua população de negros, também segue a mesma linha. Já as regiões Sul e Sudeste, que possuem uma menor quantidade de habitantes negros comparada às outras três regiões citadas, tiveram porcentagens consideráveis. Portanto, é possível confirmar que pessoas negras compõem majoritariamente o número de vítimas por COVID-19 na maioria das regiões brasileiras, evidenciando o impacto da desigualdade.

As Figuras 4 e 5 ilustram a realidade da pandemia nas duas maiores metrópoles brasileiras. São Paulo, com aproximadamente 12 milhões de habitantes e 37\% da 


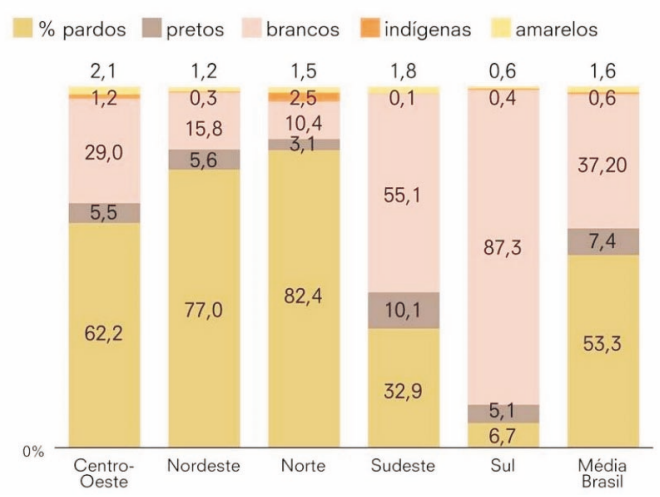

Figura 3 Mortos por COVID-19 por cor e região no Brasil

Fonte: Soares et al. (2020) — Dados do Brasil: Sivep Gripe / Opendatasus. Julho de 2020.

população de negros, e Rio de Janeiro, 7 milhões de habitantes e com $47,4 \%$ de pessoas negras (IBGE, 2019b), as quais representaram o estudo de caso deste trabalho.

Na Figura 4, é analisada a variação entre os óbitos por COVID-19, os bairros e a porcentagem de moradores negros da cidade de São Paulo. É perceptível que os bairros com a maior quantidade de mortes possuem uma porcentagem relevante de moradores negros, além de serem bairros periféricos, com baixa qualidade de infraestrutura, saúde e salubridade, condições que impossibilitam a plena prevenção da doença como é o caso de Brasilândia, que possui a maior quantidade de mortes até a data de 30 de abril de 2020. Grajaú, com a maior porcentagem de pessoas negras residentes, está em $5^{\circ}$ lugar no ranking de mais óbitos por COVID-19, além do caso de Cidade Tiradentes, em $6^{\circ}$ lugar.

Na Figura 5, que retrata o caso da cidade do Rio de Janeiro, é possível observar que o bairro com mais mortes - Campo Grande - até 5 de maio de 2020, possuía a maioria de sua população de pessoas negras. Seguida de Bangu, em $3^{\circ}$ lugar em óbitos e Realengo, em $4^{\circ}$ lugar, também com uma porcentagem relevante de negros. Além do bairro com a maior quantidade de moradores negros - Santa Cruz - que ocupa a 6 a posição nesse ranking. Tais localizações são periféricas e de condições precárias. Algumas regiões possuem déficits de saneamento básico, infraestrutura e acesso à saúde pública, o que dificulta inteiramente a prevenção do coronavírus. Além do fato de que os moradores necessitam de realizar suas atividades laborais; porém, dificilmente, podem ou possuem condições de fazê-las em modelo de home office.

Contrapondo ao bairro com menos número de mortes - Recreio dos Bandeirantes - que é considerado um dos bairros mais nobres da cidade, o Rio de Janeiro, 


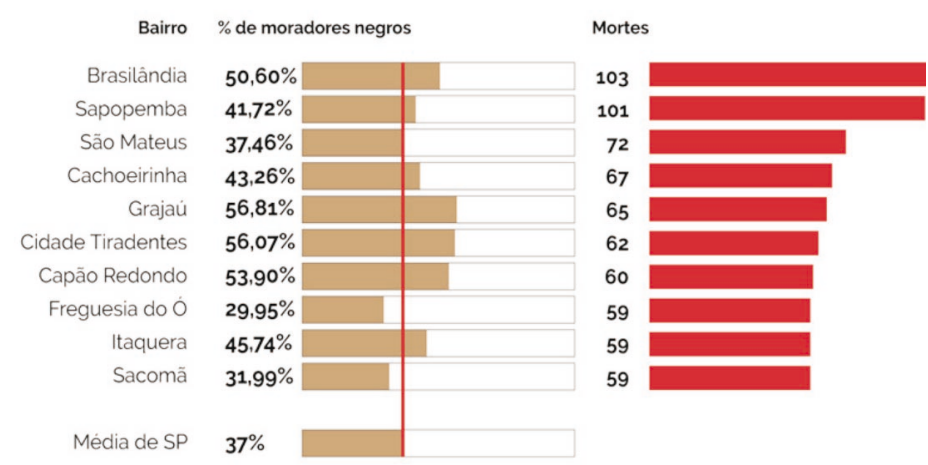

Figura 4 Mortes por COVID-19 Bairros em de São Paulo

Fonte: Muniz et al. (2020) - Agência Pública/ Secretaria de Saúde de São Paulo. Dados referentes a 30 de abril de 2020 .

diferentemente de São Paulo, possui o $2^{\circ}$ lugar em mortes em um bairro nobre da cidade - Copacabana - que possui uma quantidade menor de moradores negros, porém esse dado pode ser explicado pelo fato de Copacabana ser considerado o bairro mais idoso do país, com 43.431 moradores com 60 anos ou mais (IBGE, 2010a), os quais representam o maior grupo de risco. Além do fato de que a pandemia, inicialmente, atingiu a classe alta, devido a ter chegado do exterior para o Brasil.

Os aspectos do racismo estrutural atrelados à pandemia não são se restringem ao Brasil, apesar de possuir as suas particularidades. Países com histórico de escravidão como os Estados Unidos apresentaram, nesta crise da COVID-19, semelhanças com o caso brasileiro. Nos Estados Unidos, parte da população negra vivência condições precárias, que as expõem ao vírus. De acordo com os autores Millett et al. (2020) existe um padrão de infecção e mortalidade da população em vários estados americanos, nos quais as mortes relatadas de negros por COVID-19, são desproporcionalmente maiores comparadas com os outros grupos étnicos.

Uma pesquisa realizada pelo laboratório americano APM Research Lab indicou que, nos Estados Unidos, os negros têm morrido 2.3 vezes a mais que os brancos de COVID-19. A cada 100 mil pessoas, 65.8 negros morrem dessa doença, comparando aos brancos com um dado de 20,7 por 100 mil (APM Research Lab Staff, 2020). Contudo, apesar de a pandemia ser um evento recente e estar em curso, é observável que, nos Estados Unidos, existem inúmeros estudos em andamento sobre a vulnerabilidade da população negra à COVID-19, mapeando diferentes cidades e estados. Postura diferente adotada no Brasil, em que a base de dados é limitada e se restringe às grandes cidades no início da pandemia (Rio de Janeiro e São Paulo). 


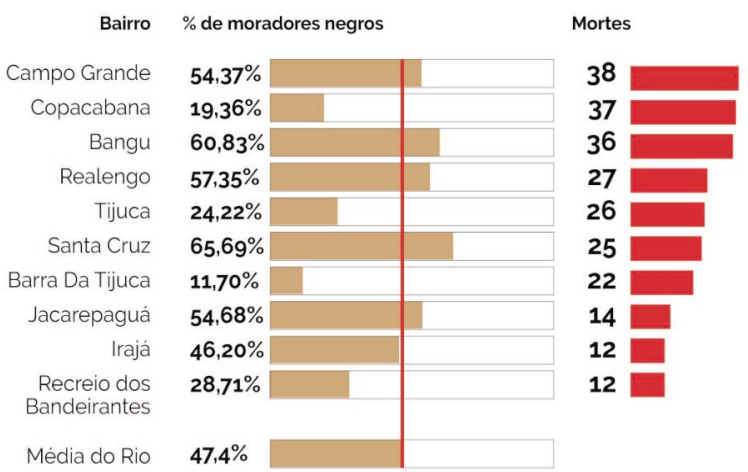

Figura 5 Mortes por COVID-19 em bairros do Rio de Janeiro

Fonte: Muniz et al. (2020) - Agência Pública/ Secretaria de Saúde do Rio de Janeiro. Dados referentes a 5 de maio de 2020.

A omissão do governo frente a essa realidade pode ser debatida à luz dos conceitos de biopolítica de Foucault e necropolítica - política da morte - de Mbembe. Para Foucault (1979/2008), a biopolítica funciona mediante a ideia de controle e condução da vida na qual cabe ao Estado a decisão de quem deve morrer ou viver, utilizando de sua soberania institucional para isso. Esse controle categoriza a distribuição dos seres humanos em grupos e subgrupos e uma divisão biológica entre eles, o que Foucault denomina de "racismo" e que, segundo Mbembe, é uma tecnologia do biopoder.

"Com efeito, em termos foucaultianos, racismo é acima de tudo uma tecnologia destinada a permitir o exercício do biopoder, 'aquele velho direito soberano de morte'." (Mbembe, 2016, p.128). Na economia do biopoder, a função do racismo é regular a distribuição da morte e tornar possíveis as funções assassinas do Estado. Mbembe citando Foucault (1997), afirma que o biopoder é "a condição para aceitabilidade do fazer morrer (Mbembe, 2016, p. 128).

Por conseguinte, no momento em que o Estado moderno permite a existência de pessoas vivendo sob condições precárias, morando em locais periféricos, que perdem a vida seja por descuido institucional ou por assassinato pelo Estado - como a letalidade policial -, isso representa a necropolítica, deixar para morrer um grupo social, um grupo que possui uma determinada etnia (Mbembe, 2016). Pode-se falar, no Brasil, em genocídio (Brum, 2020), por parte do governo, em função da negligência diante da forma como a pandemia da COVID-19 foi gerenciada. Devido a atitudes de negação científica, propagação de fake newws, incentivo ao não uso de máscara, contra as medidas de lockdown e atraso da vacinação, a população brasileira adoece e morre mais rapidamente, principalmente as populações negras e indígenas. 


\section{Conclusão}

A discussão propôs mostrar a presença do racismo estrutural no Brasil, conforme os dados, evidenciando que a população negra foi a mais afetada pela pandemia da COVID-19 no Brasil. A face nefasta da desigualdade social está diretamente correlacionada a esses óbitos; porém, devido à configuração social do Brasil pós-abolição, as pessoas negras se tornaram majoritariamente mais vulneráveis aos estigmas socioeconômicos e, parafraseando Fernandes (1989), os negros precisam atravessar dois grandes obstáculos no Brasil: o de raça e o de classe.

Os resultados apresentados indicaram o crescimento constante das internações e óbitos por COVID-19 entre as populações marginalizadas - em sua maioria negra - , as quais não possuem condições financeiras para custear um tratamento particular e para cumprir as exigências do isolamento social, o que as torna incapazes de combater a proliferação do vírus. Tal situação desnuda a política brasileira, que perdura um racismo institucional, vulnerabilizando esse grupo étnico a possíveis desastres naturais ou sociais. Fato que não só ocorre atualmente, mas se sucedeu na pandemia da Gripe Espanhola, a qual teve seu foco no país em 1918 em que negros e imigrantes foram vítimas consideráveis dessa mazela. A COVID-19 expôs duramente essa realidade, e demanda uma mudança urgente no padrão estrutural da sociedade brasileira.

Contudo, essa população que é perpetuamente deixada à margem, em uma situação de calamidade de saúde como a atual pandemia do coronavírus, torna-se mais susceptível a perder a vida, equivalendo à discussão da biopolítica, devido à priorização de determinadas vidas em relação às outras, e a necropolítica como forma de deixar determinadas populações ao desalento. O que, de fato, foi confirmado com a chegada do vírus no Brasil, e em outros países com problemas raciais e sociais engendrados em sua estrutura como, por exemplo, os Estados Unidos, que apresentaram altos índices de óbitos entre a população afro-americana. Como citou Nabuco (2012), em seus estudos sobre os movimentos abolicionistas, todos os brasileiros são responsáveis pela escravidão, assim como pelo racismo subjacente desse sistema. "Atacar a bandeira negra é ultrajar a nacional." (Nabuco, 2012, p. 170).

O mundo, agora, aposta na imunização pela vacina para amenizar as consequências da COVID-19. Em janeiro de 2021, mais de 40 países já iniciaram o processo de vacinação, enquanto o Brasil, sequer, possuía uma previsão exata. Isso ocorre devido ao presidente não confiar em determinados laboratórios por questões políticas (G1, 2020b) e por já ter um histórico de negação da pandemia, propagando informações contra as recomendações de especialistas, além de aparecer publicamente sem utilizar máscara, o que incentiva uma parcela da população a repetir seu comportamento. Além das terríveis consequências que a doença trouxe ao Brasil, elas são 
incessantemente prolongadas pelas ações do Governo Federal. Portanto, a guerra contra a COVID-19 não é somente imunológica, mas conjuntamente à incumbência dos aspectos políticos, raciais e socioeconômicos.

\section{Notas}

Por decisão pessoal, as autoras do texto não escrevem segundo o novo acordo ortográfico.

\section{Referências}

Adamo, S. (1983). The broken promise: race, health, and justice in Rio de Janeiro, 1890-1940 (Tese de Doutoramento). The University of New Mexico, Albuquerque.

Almeida, S. (2018). O que é racismo estrutural? Editora Letramento.

APM Research Lab Staff (2020, 24 de junho). The color of coronavirus: Covid-19 deaths by race and ethnicity in the U.S. (next update July 8, 2020) APM Research Lab. https://www.apmresearchlab.org/covid/deaths-by-race

Azevedo, M., \& Coly, S. (2020, 26 de junho). Pandemia do Corona vírus acentua o racismo estrutural no Brasil. Carta Capital.

https://www.cartacapital.com.br/opiniao/pandemia-do-coronavirus-acentua-o-rac ismo-estrutural-no-brasil/

Baqui, P., Bica, I., Marra., Ercole, A., \& van der Schaar, M. (2020). Ethnic and regional variations in hospital mortality from COVID-19 in Brazil: a cross-sectional observational study. The Lancet Glob Health, 8(8), e1018-e1026.

https://doi.org/10.1016/S2214-109X(20)30285-0

Bassanezi, M. S. C. B. (2012, outubro). Uma trágica primavera. A epidemia de gripe de 1918 no Estado de São Paulo, Brasil. V Congresso da Associação Latino-Americana de População, Montevideo, Uruguai. http://www.alapop.org/Congreso2012/DOCSFINAIS_PDF/ALAP_2012_FINAL251.pdf

Bolsanello, M. A. (1996). Darwinismo social, eugenia e racismo "científico": sua repercussão na sociedade e na educação brasileira. Educar, (12), 153-165. https://www.scielo.br/pdf/er/n12/n12a14.pdf

Brum, E. (2020, 22 de julho). Há indícios significativos para que autoridades brasileiras, entre elas o presidente, sejam investigadas por genocídio. EL PAÍS. https:// brasil.elpais.com/brasil/2020-07-22/ha-indicios-significativos-para-que-autorid ades-brasileiras-entre-elas-o-presidente-sejam-investigadas-por-genocidio.html

Cancian, N. (2020, 31 de dezembro). Três ministros da Saúde e uma pandemia: o ano em que ficamos doentes. Folha de São Paulo.

https://www1.folha.uol.com.br/cotidiano/2020/12/tres-ministros-da-saude-e-uma -pandemia-o-ano-em-que-ficamos-doentes.shtml 
Capodeferro, M., \& Smiderle, J. J. (2020). A resposta do setor de saneamento no Brasil à COVID-19. Revista de Administração Pública, 54(4), 1022-1036.

https://www.researchgate.net/publication/343426814_A_resposta_do_setor_de_s aneamento_no_Brasil_a_COVID-19

Cardoso, L. (2008). O branco "invisível": um estudo sobre a emergência da branquitude nas pesquisas sobre as relações raciais no Brasil (Período: 1957-2007) (Dissertação de Mestrado). Universidade de Coimbra.

https:// dlc.library.columbia.edu/catalog/ldpd:504811/bytestreams/content/content ?filename=LOUREN\%C3\%87O+DA+CONCEI\%C3\%87\%C3\%83O+CARDOSO.pdf

Carmichael, S., \& Hamilton, C. (1967). Black power: the politics of liberation in America. Vintage.

Conselho Nacional de Saúde (2020, 28 de fevereiro). Saúde perdeu R 20 bilhões em 2019 por causa da EC 95/2016. Conselho Nacional de Saúde - Notícias.

http:/ / www.conselho.saude.gov.br/ ultimas-noticias-cns/1044-saude-perdeu-r-20 -bilhoes-em-2019-por-causa-da-ec-95-2016

Croda, J., Oliveira, W. K. de, Frutuoso, R. L., Mandetta, L. H., Baia-da-Silva, D. C., Brito-Sousa, J. D., Monteiro, W. M., \& Lacerda, M. V. G. (2020). COVID-19 in Brazil: advantages of a socialized unified health system and preparation to contain cases. Revista da Sociedade Brasileira de Medicina Tropical [online], 53, 1-6. https:/ / doi.org/10.1590/0037-8682-0167-2020

d'Adesky, J. (1997). Pluralismo étnico e multiculturalismo. Afro-Ásia.

Decreto $\mathrm{n}^{\circ}$ 46.980/2020, de 19 de março. Governador atualiza as medidas de enfrentamento da propagação do novo Coronavírus. Diário Oficial do Estado do Rio de Janeiro, Executivo, Parte I, 051-B. https:/ / www.legisweb.com.br/legislacao/ ?id=391093

Decreto ${ }^{\circ}$ 64.881/2020, de 22 de março. Decreta quarentena no Estado de São Paulo, no contexto da pandemia do COVID-19 (Novo Coronavírus), e dá providências complementares. Diário Oficial, Estado de São Paulo, Executivo, Seção I, Vol. 130, 57, 1. https:/ / www.al.sp.gov.br/norma/193361

Fernandes, F. (1989). Significado do protesto negro (Coleção polêmicas do nosso tempo, Vol. 33). Cortez/Autores Associados.

Fernandes, F. (2008). A integração do negro na sociedade de classes: o legado da "raça branca" (5 ed., Vol. 1). Globo.

Foucault, M. (2005). Em Defesa da Sociedade. Curso no Collège de France (1975- 1976) (M. E. Galvão, Trad.). Martins Fontes. (Obra originalmente publicada em 1976)

Foucault, M. (2008). Nascimento da biopolítica. Curso dado no Collège de France (1978-1979)

(E. Brandão, Trad.). Martins Fontes. (Obra originalmente publicada em 1979)

Freyre, G. (2006). Casa-Grande e Senzala (51 ${ }^{\mathrm{a}} \mathrm{ed}$.). Global Editora.

G1. (2020a, 19 de março). Governo do RJ confirma a primeira morte por coronavírus. G1. https://g1.globo.com/rj/rio-de-janeiro/noticia/2020/03/19/rj-confirma-a-primei ra-morte-por-coronavirus.ghtml

G1. (2020b, 27 de dezembro). "Não dou bola para isso", diz Bolsonaro sobre atraso do Brasil na vacinação contra Covid-19. G1. 
https://g1.globo.com/politica/noticia/2020/12/26/nao-dou-bola-para-isso-diz-b olsonaro-sobre-brasil-estar-atras-em-vacinacao-da-covid-19.ghtml

Holanda, S. B. (1963). Raízes do Brasil (4 ${ }^{\mathrm{a}}$ ed.). Editora da Universidade de Brasília.

IBGE, Instituto Brasileiro de Geografia e Estatística. (2010a). Sinopse do Censo Demográfico 2010. Rio de Janeiro.

https:/ / censo2010.ibge.gov.br/ sinopse/index.php?dados=1\&uf=33

IBGE, Instituto Brasileiro de Geografia e Estatística. (2010b). Censo Demográfico 2010, Tabela 3175 - População residente, por cor ou raça, segundo a situação do domicílio, o sexo e a idade. https:/ / sidra.ibge.gov.br/tabela/3175\#resultado

IBGE, Instituto Brasileiro de Geografia e Estatística. (2019a). Desigualdades Sociais por Cor ou Raça no Brasil (Estudos e Pesquisas. Informação Demográfica e Socioeconômica - N. 41). https:/ / biblioteca.ibge.gov.br/index.php/ bibliotecacatalogo?view=detalhes\&id=2 101681

IBGE, Instituto Brasileiro de Geografia e Estatística. (2019b). Estimativa da População 2019. https://ftp.ibge.gov.br/Estimativas_de_Populacao/Estimativas_2019/POP2019_2 0201006.pdf

Javorcik, B. (2020, 4 de maio) Long term consequences of COVID-19 [Comunicação]. The World BanK: Will COVID-19 Reshape the Global Economy?, Online https://www.worldbank.org/en/events/2020/05/04/will-covid-19-reshape-theglobal-economy

Jesus, V. (2020). Racializando o olhar (sociológico) sobre a saúde ambiental em saneamento da população negra: um continuum colonial chamado racismo ambiental. Saúde e Sociedade [online], 29(2), e180519. https:/ / www.scielo.br/pdf/sausoc/v29n2/1984-0470-sausoc-29-02-e180519.pdf

Kalckmann, S., Santos, C. G. dos, Batista, L. E., \& Cruz, V. M. da (2007). Racismo institucional: um desafio para a eqüidade no SUS? Saúde e Sociedade, 16(2), 146-155. https://www.scielosp.org/article/sausoc/2007.v16n2/146-155/

López, L. C. (2012). The concept of institutional racism: applications within the healthcare field. Interface - Comunicação, Saúde, Educação, 16(40), 121-134.

Madeiro, C. (2020, 2 de junho). Covid mata 55\% dos negros e 38\% dos brancos internados no país, diz estudo. UOL Notícias.

https:/ / noticias.uol.com.br/saude/ultimas-noticias/redacao/2020/06/02/covid-mata54-dos-negros-e-37-dos-brancos-internados-no-pais-diz-estudo.htm?cmpid=copiaecola

Maia, K. S., \& Zamora, M. H. N. (2018). O Brasil e a Lógica racial: Do branqueamento à produção de subjetividade do racismo. Psicologia Clínica, 30(2), 265-286. http://pepsic.bvsalud.org/pdf/pc/v30n2/05.pdf

Mbembe, A. (2016). Necropolítica, Arte E Ensaios, Revista do ppgav/eba/ufrj, (32), 123-151. https://revistas.ufrj.br/index.php/ae/article/view/8993

Millett, G. A., Jones, A.T., Benkeser, D., Baral, S., Mercer, L., Beyrer, C., Honermann B., Lankiewicz, E., Mena, L., Crowley, J. S., Sherwood, J., \& Sullivan, P.S. (2020). Assessing differential impacts of COVID-19 on black communities. Annals of Epidemiology, 47, 37-44. https:/ / pubmed.ncbi.nlm.nih.gov/32419766/ 
Ministério da Saúde. (2017). Política Nacional de Saúde Integral da População Negra. Uma política para o SUS ( $3^{\mathrm{a}}$ ed.). Editora do Ministério da Saúde.

https://bvsms.saude.gov.br/bvs/publicacoes/politica_nacional_saude_populaca o_negra_3d.pdf

Ministério do Desenvolvimento Regional. (2018). Base de Dados do Sistema Nacional de Informações sobre Saneamento - Séries Históricas.

https:/ / basedosdados.org/dataset/sistema-nacional-de-informacoes-sobre-sanea mento-snis

Muniz, B., Fonseca, B., \& Pina, R. (2020, 6 de maio). Em duas semanas, número de negros mortos por coronavírus é cinco vezes maior no Brasil. Agência Pública.

https:/ /apublica.org/2020/05/em-duas-semanas-numero-de-negros-mortos-por-coro navirus-e-cinco-vezes-maior-no-brasil/?mc_cid=d1c4b83e9e\&mc_eid=97864c06e1

Nabuco, J. (2012). 1849-1910. O abolicionismo / Joaquim Nabuco. Vozes.

Nascimento, A. (1978). O genocídio do negro brasileiro: processo de um racismo mascarado. Paz e Terra.

Oliveira, A. S., \& Carvalho, A. R. (2017). A desigualdade racial do brasil: o racismo estrutural e o determinismo social. Revista Jurídica Direito, Sociedade e Justiça. 5(1), 228-230. https:/ / periodicosonline.uems.br/index.php/RJDSJ/article/view/2242

ONU, Organização das Nações Unidas. (1965). Convenção Internacional sobre a Eliminação de Todas as Formas de Discriminação Racial. (Ratificado pelo Brasil em 27 de março de 1968). Presidência da República.

http://www.planalto.gov.br/ccivil_03/decreto/1950-1969/D65810.html

Partington, R. (2020, 5 de maio). Inflation collapses around the world amid coronavirus pandemic. The Guardian.

https://www.theguardian.com/business/2020/may/05/inflation-collapses-worl d-coronavirus-pandemic-global-economy-business-great-depression-recession

Phillips, T., \& Briso, C. B. (2020, 27 de março). Bolsonaro's anti-science response to coronavirus appals Brazil's governors. The Guardian.

www.theguardian.com/world/2020/mar/27/jair-bolsonaro-coronavirus-brazil-g overnors-appalled

Piketty, T. (2014). O capital no Século XXI (1 $1^{\text {a }}$ ed.). Intrínseca.

Reuthers, (2021). Acompanhamento da disseminação do novo coronavírus. Reuthers Graphics. https://graphics.reuters.com/CHINA-HEALTH MAP/0100B59S39E/index.html

Schucman, L. V. (2014). Sim, nós somos racistas: estudo psicossocial da branquitude paulistana. Psicologia \& Sociedade, 26(1), 83-94.

https://doi.org/10.1590/S0102-71822014000100010

Schwarcz, L. M., \& Starling, H. M. (2015). Brasil: Uma biografia. Companhia das Letras.

Silva, N. N., Favacho, V. B. C., Boska, G. A., Andrade, E. C., Merces, N. P., \& Oliveira, M. A. F, (2020). Acesso da população negra a serviços de saúde: revisão integrativa. Revista Brasileira de Enfermagem, 73(4), e20180834.

https://www.scielo.br/pdf/reben/v73n4/pt_0034-7167-reben-73-04-e20180834.pdf 
Soares, M., Cravo, A., \& Tatsch, C. (2020, 03 de julho). Dados do SUS revelam vítima-padrão de Covid-19 no Brasil: homem, pobre e negro. O Globo ÉPOCA. https://oglobo.globo.com/epoca/sociedade/dados-do-sus-revelam-vitima-padra o-de-covid-19-no-brasil-homem-pobre-negro-24513414

Wedderburn, C. M. (2007). O racismo através da história: da antiguidade à modernidade. Ed. Mazza.

http://www.ammapsique.org.br/baixe/O-Racismo-atraves-da-historia-Moore.pdf

WHO, World Health Organization. (2020a). Novel Coronavirus (2019-nCoV) Situation report (N.1).

https://www.who.int/docs/default-source/coronaviruse/situation-reports/2020 0121-sitrep-1-2019-ncov.pdf

WHO, World Health Organization. (2020b). Coronavirus disease 2019 (COVID-19) situation report (N.51).

https://www.who.int/emergencies/diseases/novel-coronavirus-2019/situation-r eports

Wu, Y., Guo, C., Tang, L., Hong, Z., Zhou, J., Dong, X., Yin, H., Xiao, Q., Tang, Y., Qu, X., Kuang, L., Fang, X., Mishra, N., Lu, J., Shan, H., Jiang, G., \& Huang, X. (2020). Prolonged presence of SARS-CoV-2 viral RNA in faecal samples. The Lancet Gastroenterology \& Hepatology, 5(5), 434-435.

https:/ / doi.org/10.1016/S2468-1253(20)30083-2

Data de submissão: 31/08/2020 | Data de aceitação: 17/06/2021 